\title{
Research on Innovative Training Methods for Frontline Employees in High-Technology Department of Power Enterprises and the Practices
}

\author{
Zhang Xilin ${ }^{1,}$, Xu Shouchen ${ }^{2, b}$ \\ 1. State Grid Jilin Electric Power Company Limited Changchun Power Supply Company , \\ Changchun, 130021, China \\ 2. State Grid the Senior Training Center, Beijing, 100085, China \\ aemail: xilinzhang@21cn.com, bemail: shouchen-xu@sohu.com
}

Keywords: Power Supply Enterprises; Dispatching Department; Employee Training

\begin{abstract}
Based on the actual situation of the dispatching department of power enterprises, this paper discusses the objectives of employee training, its organizational form, training forms, training content, assessment requirements as well as incentives and restriction. The actual training results test to the effectiveness of the methods.
\end{abstract}

\section{Introduction}

The dispatching department of power supply enterprises is a knowledge-intensive department, composed of such four specialties as power grid dispatching, relay protection, communication engineering and automation. With the continuous expansion of power grids, the shortage of engineers and technicians, short-term professional experience and other problems become pronounced. The training of engineers and technicians is therefore particularly important so as to ensure the smooth progress of daily work and safety production.

\section{Training Objectives ${ }^{[1]}$}

The training objectives are to improve employees' working stills and professional quality in order to meet the requirements for the operation, maintenance and repair of conventional and high-technology equipment; to enhance employees' professional comprehensive ability and comprehensive quality to make them complement and back up each other and meet the needs of the innovative management mode and institutional reform of enterprises; to cultivate top-notch talents and bring up a number of high-quality, high-skilled and high profile professional and technical leaders; to make employees have a deep understanding of the social responsibility and mission they undertake, and to stimulate their thirst for knowledge and creativity and to keep them striving for more and improving their competitiveness; and to become unceasingly-striving employees of power enterprises by helping them gain a wealth of knowledge, develop skills and foster noble, moral sentiments.

\section{Organizational Form ${ }^{[2]}$}

a. Include the training in the agenda of the leading group

The leading group pays high attention to the training and includes it in its agenda. When setting the work objectives for the whole year at the beginning of the year and making work arrangements, the leading group should insure that departments and specialties have the task of training.

b. Appoint a person specifically for the training

A member from the leading group is appointed to take charge of the training and the daily work of the department training. It should be clear that the ad-hoc engineer of each specialty is the first responsible person for the training of the specialty and is responsible for the concrete implementation of the training, and that the technician of the working team is the first responsible person for the training of the working team, and is responsible for the concrete implementation of 
the training.

c. Combine the uniform training guidance with the training plan with professional characteristics

The department formulates the uniform training guidance, while each specialty, working team works out its own training plan. Each specialty and working team carries out the training plan to the letter.

\section{Training Forms ${ }^{[1-3]}$}

Employee training can be carried out in the form of irregular training, regular training, special training, new employee training, competition for number one and mentor-apprentice, flexible training, in-plant training, and technical innovation-based comprehensive quality training, etc.

a. Irregular training

The professional training of employees is carried out normally by the ad-hoc engineer of each specialty and the technician of each working team. The executive of each specialty should supervise and guide the subordinates and spur them to improve their professional ability, enrich themselves with the knowledge and skills of their specialty, study specialized books, drawings and documents related to the work of their positions, and master relevant on-site conditions. On-site installation and debugging by the supplier's engineering technicians should be fully used for the operation and maintenance training of concerned professional staff in the department.

b. Regular Concentrated Training

Regular training of employees is given twice a year, respectively in the first half year (from February to March) and the second half (from November to December), according to the production characteristics of power grid enterprises. Safety training and assessment is conducted in February to March every year. The conflict between training and production is solved properly, with neither of them being neglected.

c. Special Training

A training program is conducted for a special skill. It is materialized in the form of lecturing and practical training given by the invited experienced engineer or technician, which combines theory with practice and emphasizes the training in skills so as to obtain practical effect. Special training and seminar will be held based on the documents and bulletins issued by the superiors.

d. New Employee Training

Concentrated training is conducted to acquaint new employees with the functions of the department, its organizational structure, functions of each specialty, scope of security duty and management rules and regulations. First, the members of the leading group provide new employees with a comprehensive training: brief introduction of the profile of the department and its important role in the safe production of the enterprise; clarification of the characteristics of each specialty in the department and the specific requirements for safety production. The training plan for new employees is compiled and placed on a file by the chief security officer. New employees are arranged to study the accident cases formulated by the company to draw serious lesions from various accidents and be aware of their damages to the enterprises and individuals, to learn the content of Safety Specification which is related to their own specialty, to familiarize themselves with the safety production duty, working standard and position responsibility at all levels. An examination is given after the training, and the exam results are reported to the superiors and kept on a file. Those who pass the examination are assigned to each specialty for technical training internship. After assigned to each working team, new employees will have a third-level training by their technician, who works out a one-year training plan, assesses them at different stages and keeps the results on a file.

\section{Training Content ${ }^{[4-8]}$}

Systematic training should be conducted for each specialty according to its own technical requirements and those requirements of Technical Grade Standards for Workers in Power Industry and verification of professional technical ability in order to make employees know about, study and 
master the knowledge and skills necessary for their positions and specialties. For the technical backbones of the specialty, they participate in the training in the professional knowledge and skills of relevant positions within the specialty to master those knowledge and skills and thus be mutually complementary. Professional technical backbones also have trainings in knowledge and skills of related specialties in addition to the trainings in their own specialty. The staff receives trainings in work ethic, corporate culture and humanistic knowledge to accumulate knowledge and get prepared for the cultivation of noble moral sentiments.

Attention is focused on the actual effect, and stress is laid on the actual results of the training. Therefore, the training content concerns the problems in production of each specialty that need to be solved urgently, and obvious results can be achieved after the training. Meanwhile, the training in the basic knowledge of computer is conducted according to the requirements of the development of modern society, and produces good results.

Directors of working teams are trained. Excellent employees with the actual experience in managing working teams are invited to give special reports, such as How to Be A Good Director of Working Team or Group, How to Handle the Relationship between Superior and Subordinate, and Security Duty of Director of Working Team. Experts and scholars are invited to lecture on the scientific knowledge and ideas of business management.

\section{Assessment Requirements}

Learning report for any on-the-job training program conducted by the company or above should be submitted to the ad-hoc engineer of the department after the training, and the training results should be recorded on the employees' assessment cards and kept on a file. For professional training held by the department, examination is given in the form of the training question bank and expert-assigned questions, and the exam results are recorded on the employees' training assessment cards, which serve as the basis of the year-end assessment. Results of the examination of professional technical skills organized by the department are ranked by specialty. Candidates for professional examination held by the superior organizations should be selected based on professional examination. All employees participate in the competition for number one.

\section{Incentives and Restriction}

Employees who have made good marks in research test, competition, and other types of contests organized by municipal, provincial or above companies are awarded and praised, and those who have made good marks in training examinations held by the department are also awarded. The results of professional competitions for number one are regarded as one basis of appraising and selecting the most outstanding employees. Those who have scored the lowest score in the professional examination for two consecutive years receive persuasion and admonition from the leaders. Training incentive and restriction mechanism is listed in the terms of performance assessment to ensure the normalization of training.

\section{Conclusion}

To innovate the forms and connotation of employee training with the times is a permanent topic for enterprise and department managers. Therefore, it is of vital, practical significance to concentrate on the studies about improving the effectiveness, pertinence and foresight of employee training in the context of enterprises' continuous innovation of management mode and institutional reform.

\section{References}

[1] Zhang Xilin, Yang Guiying, Liu Xiaowei. Experience of Employee Training in the Dispatching Department of Power Supply Enterprises [J]. China Electric Power Education, 2010,(29):48-50. 
[2] Zhang Xilin, Zhang Hui. Practices of the Competition for Number One in Dispatching Department of Power Supply Enterprises [J]. China Electric Power Education, 2010,(36):243-244.

[3] Li Yiling, Zhang Xilin, Zhang Yan. Originality, Building of Question Bank and Practice of “Five One” Themed Training [J]. China Electric Power Education, 2010,(27):229-231.

[4] Zhang Xilin, Li Debin. Functional Requirement on EMS in District Dispatching Center and Its Algorithm [J]. China Power, 1999, (9):51-52.

[5] Zhang Xilin, Zhang Fan. Optimal Operation of 2 Duplex Winding Main Transformers [J]. China Power, 2000,(5):29-31.

[6] Zhang Xilin, Li Fen. Optimal Power Flow on Sub-transmission Lines in Large Cities [J]. China Power, 2001,(2):48-49

[7] Zhang Xilin, Huang Peixin, Zhang Jianguo. New Performance of DTS in Local Electric Grid [J]. China Power, 2006,(5):29-31.

[8] Zhang Xilin, Wan Xiaohua, Du Changyin. Rapid Positioning of Dispatching Automation System Faults [J]. Electric Power Information Technology, 2008,(4):57-59. 